\title{
Current status and perspectives of cell therapy in Chagas disease
}

\author{
Milena Botelho Pereira Soares ${ }^{1,2}$, Ricardo Ribeiro dos Santos ${ }^{1,2} /+$ \\ ${ }^{1}$ Centro de Pesquisas Gonçalo Moniz-Fiocruz, Rua Waldemar Falcão 121, 40296-710 Salvador, BA, Brasil, ${ }^{2}$ Hospital São Rafael, Salvador,
} BA, Brasil

\begin{abstract}
One century after its discovery, Chagas disease, caused by the protozoan, Trypanosoma cruzi, remains a major health problem in Latin America. Mortality and morbidity are mainly due to chronic processes that lead to dysfunction of the cardiac and digestive systems. About one third of the chronic chagasic individuals have or will develop the symptomatic forms of the disease, with cardiomyopathy being the most common chronic form. This is a progressively debilitating disease for which there are no currently available effective treatments other than heart transplantation. Like in other cardiac diseases, tissue engineering and cell therapy have been investigated in the past few years as a means of recovering the heart function lost as a consequence of chronic damage caused by the immune-mediated pathogenic mechanisms elicited in individuals with chronic chagasic cardiomyopathy. Here we review the studies of cell therapy in animal models and patients with chronic Chagas disease and the perspectives of the recovery of the heart function lost due to infection with $\mathrm{T}$. cruzi.
\end{abstract}

Key words: Chagas disease - cardiomyopathy - cellular therapy - stem cells - tissue inflammation - fibrosis

Infection with Trypanosoma cruzi causes American trypanosomiasis or Chagas disease, which, despite the efforts of the past 100 years since its discovery, remains a major health problem in Latin America. In the acute phase of the infection, parasites are easily found replicating in different tissues and organs (Fig. 1A) as well as circulating in the blood. During this phase of infection, anti-T. cruzi adaptive immune responses reduce and control the parasitism but do not cause its complete eradication (Soares et al. 2001).

The acute phase is followed by a chronic phase, the indeterminate form of Chagas disease, in which patients are usually free of clinical symptoms. Most of the individuals will remain in this phase throughout the rest of their lives. However, about $30 \%$ of chagasic patients develop a chronic symptomatic form of the disease after a time period ranging from a few months to decades (Dias \& Coura 1997).

Chronic chagasic cardiomyopathy (CCC) is the most prevalent form of chronic symptomatic disease and constitutes one of the leading causes of heart failure in several Latin American countries. It is characterised by an intense myocarditis, myocytolysis, neuronal destruction and replacement of lost cardiac tissue by fibrosis. These pathological changes may lead to cardiomegaly, apical aneurism and arrhythmias, consequently causing heart failure and death (Köberle 1968).

The pathological basis of CCC has been a matter of intense debate in recent decades (Soares et al. 2001).

Financial support: CNPq, FAPESB, RENORBIO, FINEP, MCT + Corresponding author: ricardoribeiro@bahia.fiocruz.br Received 19 March 2009

Accepted 28 May 2009
Some authors propose that the pathogenic inflammatory response is exclusively directed against $T$. cruzi antigens at sites of parasite persistence (Higuchi 1997, Tarleton 2001). However, the lack of correlation between the degree of tissue parasitism and the inflammatory response has led to a hypothesis that CCC is an autoimmune disease triggered in some individuals by $T$. cruzi infection (Cunha-Neto \& Kalil 1995, Leon \& Engman 2001, Pontes de Carvalho et al. 2002). Nonetheless, it is likely that these two components are associated (Soares et al. 2001) and T-cell mediated responses against cardiac antigens have been reported upon stimulation with T. cruzi (Ribeiro dos Santos et al. 1992, 2001, Leon et al. 2004).

Benznidazole is the main antiparasitic drug available for the etiological treatment of Chagas disease. This drug is mainly effective in parasite eradication in the acute phase of infection but not in the prevalent chronic stage of the disease (Cançado 2002). Due to its high toxicity and low efficacy in parasite eradication, the use of benznidazole during the chronic phase of infection has been highly debated. However, the reduction in parasite burden due to the administration of benznidazole during the chronic infection was associated with a reduction in the cardiac alterations in mice with CCC (Garcia et al. 2005). Thus, there is a great need for the development of new anti-T. cruzi agents that are less toxic and more effective (Moreira et al. 2009).

Patients with CCC may have some benefits from drugs such as beta-blockers, ACE inhibitors and diuretics. However, the only effective treatment available for patients with heart failure due to Chagas disease is heart transplantation. This procedure is not only difficult in these patients due to the high costs and scarcity of donated organs but also because the use of immunosuppressive drugs after transplantation may reactivate the latent infection. Thus, millions of chagasic cardiopaths in Latin American countries will inexorably evolve to 
death without any therapeutic option. Therefore, the development of new therapies for patients with $\mathrm{CCC}$ is of great social and economical relevance.

The discovery of stem cells capable of differentiating into specialised cell types has opened new avenues for the treatment of degenerative and traumatic disorders, including heart failure. In the case of Chagas disease, this therapy is being developed not to kill the infectious agent, but rather to ameliorate the heart disease caused by chronic infection with $T$. cruzi. Instead of replacing the heart of chagasic individuals with heart failure, the repair of the heart with the patient's own cells became an attractive option to be investigated. In this review, we will focus on the new approaches that may lead to the regeneration of the heart tissue damaged by the pathological processes caused by infection with $T$. cruzi.

\section{Stem cells}

Stem cells are non-specialised cells that possess two main characteristics: the ability to self-renew, thereby maintaining a pool of stem cells, and the potential for differentiation into specialised cells. There are two main types of stem cells considered for tissue regeneration, namely embryonic and adult stem cells. Embryonic stem cells (ESCs) are derived from the inner cell mass of blastocyst-stage embryos, whereas adult stem cells, such as mesenchymal stem cells (MSCs), can be isolated from post-natal tissues, expanded in vitro as adhesion-derived cells and induced to differentiate into multiple cell types (Alison \& Islam 2009).

During the past decade, adult stem cells have been isolated from most tissues in the body. The sources commonly used for experimental studies are the bone marrow, adipose tissue, dental pulp, umbilical cord blood and placenta. Studies comparing the properties and the potential induction of tissue regeneration are still being carried out and may in the future allow for the selection of the most appropriate cell type for treating a particular disease.

Stem cells can be classified as totipotent, pluripotent or multipotent. A multipotent cell can give rise to multiple cell types not restricted to a single germ layer. A pluripotent cell should be able to give rise to all cell types that are found in an adult organism. A totipotent cell is a cell that can produce an entire organism including extra-embryonic membranes and placenta. In addition, the term progenitor cell has also been applied to tissue-specific stem cell populations, such as cardiac stem cells (Kajstura et al. 2008).

Tissue-specific (resident) stem cells play a physiological role in tissue renewal and regeneration. In addition, bone marrow derived circulating stem and precursor cells can migrate into organs such as the liver and heart, as shown in studies of chimeric mice and patients (Bayes-Genis et al. 2007, ten Hove et al. 2007). When chronic injuries cause persistent damage, the repair promoted by endogenous or circulating stem cells is usually not sufficient to retain the organ's functionality. Aging also causes a decline in stem cell populations (Ballard \& Edelberg 2008) and, consequently, the regenerative capacity of patients more often affected by chronic de- generative diseases is decreased with age. Thus, there is a great need for developing new therapies based on stem cells and cell factors to directly repair or improve the endogenous repair mechanisms of damaged organs (Taylor \& Zenovich 2008).

\section{Reconstructing the heart}

The search for methods to repair the damaged heart has been the subject of intense investigation. Myoblasts (Scorsin et al. 2000) and ESCs (Hodgson et al. 1994, Klug et al. 1996, Laflamme \& Murry 2005, Laflamme et al. 2005, Menard et al. 2005) were tested in animal models of cardiac lesions caused by ischemia. Although improvement of heart function was observed after treatment with these cell types, their clinical use at the moment is impaired due to safety and ethical issues. Treatment with ESCs, besides all the polemics surrounding its clinical application, caused the development of teratocarcinomas in animal models (Cao et al. 2006), whereas myoblasts caused arrhythmias in patients due to the lack of gap junction establishment between these cells and resident cardiomyocytes (Reinecke et al. 2000). Thus, the use of other sources of adult cells that can allow for fast translation into the clinical setting has been investigated.

The bone marrow became an attractive source of cells for tissue regeneration after the discovery of pluripotent stem cells in this tissue (Pittenger et al. 1999), opening up the possibility of applying their plasticity to generate new cardiomyocytes (Makino et al. 1999). In addition, due to previous clinical experience in bone marrow transplantation and its easy accessibility for collection, this is a readily available source for autologous therapy. Orlic et al. (2001) published the first report showing the potential use of bone marrow-derived cells (BMC) in the regeneration of damaged myocardium by acute ischemia in mice. Several reports demonstrating in animal models of heart diseases the repair of cardiac lesions as well as functional improvement of heart function were published shortly thereafter (Kocher et al. 2001, Wang et al. 2001, Toma et al. 2002, Olivares et al. 2004).

Although interesting results were obtained in animal models of disease, only a few cardiomyocytes derived from transplanted stem cells were found, indicating that their mechanism of action may be due to paracrine effects. These include the induction of angiogenesis, recruitment of circulating stem cells and activation of resident cardiac stem cells (Cheng \& Yau 2008).

The development of new methodologies in tissue bioengineering may allow for the reconstruction of a new heart using scaffolds of decellularised hearts in which the extracellular matrix components and vascular bed are preserved (Ott et al. 2008).

\section{Cell therapy studies in Chagas disease}

Cell therapy in animal models - During the acute infection with $T$. cruzi, a massive destruction of cardiomyocytes occurs. However, when parasitemia is controlled, a remarkable recovery of the heart can be observed. Using bone marrow chimeras, in which the bone marrow from $\mathrm{C} 57 \mathrm{Bl} / 6$ recipient mice are replaced by 
cells from EGFP transgenic C57Bl/6 mice, we observe the migration of $\mathrm{GFP}^{+} \mathrm{BMC}$ (Fig. 1B). In addition, the appearance of some $\mathrm{GFP}^{+}$cardiomyocytes can be observed (Fig. 1C, D). This indicates that BMC contribute to the repair of the myocardium after the acute infection. The presence of inflammation and cell death may represent signals for the recruitment of circulating stem cells into the chagasic heart.

Since bone marrow cells naturally migrate to the inflamed chagasic heart and contribute to the formation of new cardiomyocytes, we hypothesised that the transplantation of bone marrow cells ameliorates the myocarditis found during the chronic phase of infection. To investigate the effects of cell transplantation in Chagas disease we used mice chronically infected with the myotropic Colombian T. cruzi strain (Federici et al. 1964), which develop a cardiomyopathy with histopathological and functional characteristics similar to those observed in humans (Rocha et al. 2006).

Using BMC obtained from mice transgenic for green fluorescent protein (GFP), we observed the presence of a transplanted cells in the hearts of chagasic mice (Soares et al. 2004, 2007), suggesting that, after systemic injection of BMC, chemoattractant factors released by the inflamed heart are able to promote their recruitment. In addition, a few days after transplantation, we observe the appearance of $\mathrm{GFP}^{+}$cells co-expressing $\alpha$-cardiac myosin, indicating that some of them may transdifferentiate or fuse with resident cardiomyocytes. The presence of $\mathrm{GFP}^{+}$myofibers with male and female nuclei in hearts from female recipient mice transplanted with male $\mathrm{GFP}^{+}$BMC (Fig. 1E, F) favours the hypothesis that the transplanted cells can fuse with resident cardiomyocytes. However, as in other models of cellular therapy in heart diseases, only a few cells are found in the hearts of BMC-treated mice; therefore, a direct contribution to tissue regeneration do not seem to fully explain the beneficial effects observed. A growing body of evidence indicates that most of the effects of stem cell therapy in cardiac diseases are, in fact, due to paracrine effects (Dawn et al. 2006, Cheng \& Yau 2008), which may act on resident mature cells and/or tissue-specific stem cells. In this regard, several groups have described the presence of resident cardiac stem cells (Perino et al. 2008).

Syngeneic BMCs obtained from normal littermates transplanted intravenously into chronic chagasic mice caused a significant decrease in inflammation observed two months after cell therapy in a dose-dependent fashion (Soares et al. 2004). Similar results were obtained using BMCs from chronically-infected donors and suggested that autologous BMCs could be used to treat patients with CCC.

Surprisingly, BMC therapy in the hearts of chronic chagasic mice produced a significant reduction in fibrosis (Soares et al. 2004). A nearly 60\% reduction in fibrosis was found two months after BMC therapy compared to saline-treated controls. Reduced fibrosis seems to be a common effect of BMC therapy, being also observed in other models of ischemic heart disease (Orlic et al. 2001) as well as in liver disease (Oliveira et al. 2008). The pro- duction of metalloproteases by stem cells has been previously demonstrated (Higashiyama et al. 2007); however, the specific mechanisms by which these cells directly and/or indirectly promote the degradation of fibrosis in Chagas disease remains to be clarified.

Since the decrease in inflammation observed after cell therapy in the mouse model of Chagas disease could be due to cell death, we evaluated the number of apoptotic cells in the hearts of chronic chagasic mice treated with BMC versus controls by the TUNEL assay. BMC-treated hearts had an increased number of apoptotic inflammatory cells compared to untreated chagasic controls (Soares et al. 2004). This suggests that transplanted BMCs may exert their action via immunomodulatory mechanisms. The immunosuppressive properties of bone marrow mesenchymal cells have been well de-
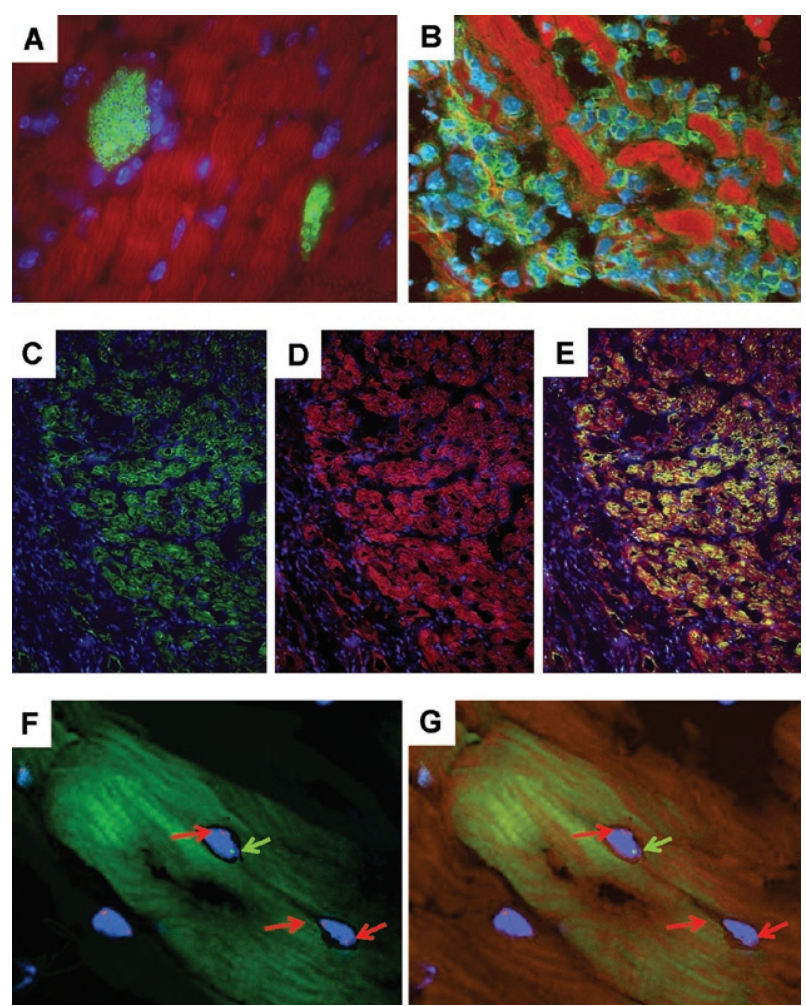

Fig. 1: presence of bone marrow-derived cells (BMC) in the hearts of chagasic mice. A: heart section of a BALB/c mouse during the acute phase of infection with Colombian strain Trypanosoma cruzi, showing parasite nests (green); B: heart section of a chimeric $\mathrm{C} 57 \mathrm{Bl} / 6$ mouse during the acute phase (30 days after infection) of infection with Colombian strain T. cruzi showing the migration of green fluorescent protein $\left(\mathrm{GFP}^{+}\right)$cells (green) to the myocardium; C, D: heart section of a chimeric C57B1/6 mouse 60 days after infection with Colombian strain T. cruzi showing the presence of $\mathrm{GFP}^{+}$cells (green) in the myocardium, co-stained with myosin (red); E, F: heart section of a chronic female C57B1/6 mouse 15 days after transplantion with $\mathrm{BMC}$ obtained from male $\mathrm{GFP}^{+}$mice. Cell therapy was performed six months after infection with Colombian strain T. cruzi. Presence of $\mathrm{GFP}^{+}$cells (green) in the myocardium, co-stained with myosin (red). Fluorescence in situ hybridization was performed to detect $Y$ (green arrow) and X (red arrow) chromosomes. Nuclei in A-F were stained with DAPI (blue). Images were captured using an Olympus spectral confocal microscope FV1000. 
scribed (Le Blanc \& Ringdén 2007) and may, therefore, contribute to the phenomenon observed in chagasic hearts after BMC therapy.

Goldenberg et al. (2008) performed a magnetic resonance imaging study to assess changes in the cardiac morphology of $T$. cruzi-infected mice after therapy with BMCs. In the model studied, the authors found that BMCtreated mice had regression of the right ventricular dilatation typically observed in the chagasic mouse model.

It is not known at the moment which bone marrow cell population is responsible for the observed effects. The mononuclear-enriched cell fraction used in the mouse model of CCC is highly heterogeneous and contains mature cell populations as well as various types of stem and precursor cells, including mesenchymal cells. Therefore, it is possible that more than one population acts to improve the heart tissue in this model.

In a rat model of T. cruzi infection using a different therapeutic scheme, improvement of the ejection fraction was observed. Rats infected with T. cruzi usually control the infection and remain in an indeterminate form of the disease. Guarita-Souza et al. (2006) used chronically infected rats showing cardiac disturbances characteristic of Chagas disease (with an ejection fraction below 37\%) and treated them with autologous skeletal myoblasts cocultured with bone marrow-derived MSCs for 14 days. This mixed cell culture was harvested and prepared for injection directly into the left ventricular wall of hearts from chagasic rats. A significant improvement in ejection fraction was observed in the animals treated with the mixed cell preparation, whereas the control group, which received only an injection of culture medium, showed no significant improvement after injection. In addition, a decrease in left ventricular end-diastolic volume and left ventricular end-systolic volume were also observed in cell-treated rats.

Histopathological analysis of heart sections of rats treated with co-cultured cells suggests the presence of myogenesis and angiogenesis (Carvalho et al. 2006). Thus, in addition to improvements in heart function, these are two desired effects of combined cell therapy for the recovery of damaged chagasic hearts. However, the use of skeletal myoblasts has been previously associated with the appearance of arrhythmias (Reinecke et al. 2000). Therefore, it is possible that the use of this kind of therapy in humans may cause conduction disturbances in chagasic patients.

Use of granulocyte-colony stimulating factor ( $G$ $C S F)$ in experimental Chagas disease - The process of chronic inflammation that leads to a progressive destruction of the heart may take a few years or even decades. When individuals with $\mathrm{CCC}$ evolve to heart failure, their hearts have suffered intense remodelling processes due to continuous tissue aggression from immune-mediated mechanisms. Therefore, one administration of cells may not be sufficient to cause a desired improvement in chronic chagasic patients. However, additional administrations may constitute an increase in costs as well as in risks for the patients due to the procedures involved in this type of therapy.
An alternative to BMC infusion is the use of cytokines that are able to mobilise bone marrow cells into the circulation, such as G-CSF. A therapy using this cytokine is attractive, because G-CSF is already used in clinical practice, has mild side effects and is a less invasive treatment than bone marrow harvest and infusion of cells into the coronary arteries. In addition, since its administration is subcutaneous, it can be used repeatedly, allowing for a boosting of the initial stimulus.

We tested the efficacy of G-CSF treatment in the mouse model of CCC. Histopathological analysis and cardiopulmonary function evaluation were performed in animals injected with G-CSF or saline as controls. Mice with CCC treated with three cycles of G-CSF (5 daily subcutaneous injections) had a significant decrease in inflammation and fibrosis in the hearts when compared to saline-treated controls. Mice treated with only one cycle had little improvement in inflammation and fibrosis (SG Macambira et al., unpublished observations). Their results indicate that, in addition to the number of cells, the number of administrations should be taken into account when searching for a more effective cell therapy for Chagas heart disease. In addition, chagasic mice treated with BMC followed by one cycle of G-CSF showed a significant decrease in inflammation and fibrosis compared to animals treated only with BMCs (Fig. 2).

Several studies in models of myocardial infarction indicate that G-CSF treatment causes repair of the myocardium and improvement of heart function. This cytokine seems to exert multiple roles, including stimulation of neovascularisation (Minatoguchi et al. 2004), protection of cardiomyocytes from death by apoptosis and decreasing the size of fibrotic areas (Harada et al. 2005, Hasegawa 2006), recruitment of bone marrow derived stem cells and the generation of new cardiomyocytes (Adachi et al. 2004, Kawada et al. 2004). In our

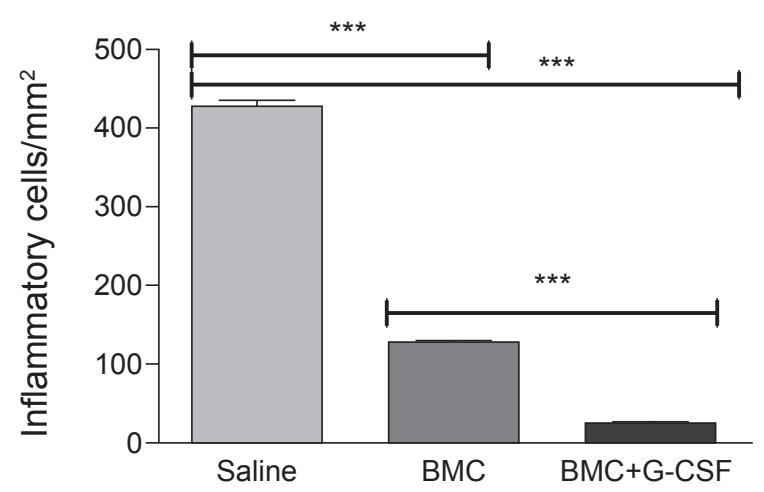

Fig. 2: effects of combined bone marrow-derived cells (BMC) and granulocyte-colony stimulating factor (G-CSF) therapy in chronic myocarditis. Chronic chagasic C57Bl/6 mice (6 months of infection) were treated with $2 \times 10^{7} \mathrm{BMC}$ by endovenous route. Thirty days later mice received one cycle of G-CSF ( $5 \mu \mathrm{g} / \mathrm{kg} /$ day during 5 days). Inflammation was quantified in the hearts two months after treatment by morphometry in H\&E-stained sections. 
model of CCC, we found that chronic chagasic hearts produce chemoattractant factors able to recruit stem cells mobilised by G-CSF into the myocardium (MBP Soares et al., unpublished observations, SG Macambira et al., unpublished observations).

A major concern in chagasic patients is the residual parasite load found in individuals during the chronic infection. In the mouse model of Chagas disease, we did not observe reactivation (appearance of patent parasitemia and intense tissue parasitism) of the infection after BMC and/or G-CSF therapy by the evaluation of blood samples and heart sections of treated mice.

Clinical trials - Based on our experimental results, we conducted a phase I clinical trial of autologous BMC therapy in patients with heart failure due to Chagas disease. Patients with New York Heart Association (NYHA) classes III or IV were included. Due to the lack of donated organs for heart transplant, most chagasic patients in this stage of heart failure will die in a few years without this therapeutic option.

Twenty eight patients were enrolled in the study in which $50 \mathrm{~mL}$ of bone marrow aspirate was collected from each patient by multiple punctures of the two iliac crests (Vilas-Boas et al. 2006). A mononuclearenriched cell fraction was then isolated by centrifugation in a ficoll-hypaque gradient and resuspended in $5 \%$ human albumin solution in saline. The $20 \mathrm{~mL}$ cell suspension was then injected slowly into the coronaries using a catheter. In addition to the cell infusion, patients received five daily administrations of G-CSF $(5 \mu \mathrm{g} / \mathrm{kg})$ beginning on the 25th day post-transplant as a boost to the therapy. Patients were evaluated before and after the procedure to determine safety as well as potential benefits of the therapy.

The first chagasic patient showed that the procedure was feasible and that no adverse effects of the therapy were observed (Vilas-Boas et al. 2004). This was further confirmed with the analysis of several clinical, biochemical and cardiologic parameters during and after the cell transplantation in a larger group of patients included in the study, who had no complications directly related to the procedure. In addition, we demonstrated the feasibility of performing puncture and coronary infusion in chronic chagasic patients (Vilas-Boas et al. 2006).

In addition to safety, the potential efficacy of the therapy was evaluated. A significant improvement in several parameters during a 60 day follow-up also suggested a potential benefit of the therapy. These included improvements in NYHA functional class, in the Minnesota quality of life questionnaire, in the distance walked in six minutes and in the left ventricular ejection fraction (Vilas-Boas et al. 2006).

In a case report by Jacob et al. (2007), the migration to the heart of injected bone marrow cells labelled with $\mathrm{mTc}$ was documented by scintigraphy. This case report showed that the transplanted BMCs are retained in the myocardium for at least $6 \mathrm{~h}$ after coronary injection.

Although the identification of the relevant cell populations may be important to improve the therapy, it is of note that the methodology used in this study is simple and less expensive than purified cell preparations. The therapy with BMC in Chagas cardiomyopathy, like in other cardiac diseases, such as acute myocardial infarction (Kang et al. 2008), seems to only partially restore the cardiac function. Nonetheless, a small gain in function seems to reflect in a significant improvement in quality of life and, therefore, should not be ignored.

The fact that CCC is characterised by the presence of diffuse inflammation may be of relevance compared to other heart diseases, such as myocardial infarction and non-chagasic dilated cardiomyopathy. In chronic lesions caused by infarction, as well as in many cases of nonchagasic dilated cardiomyopathies, inflammation is low or absent and may not properly attract cells to the site of the lesion. In addition, fibrosis in chagasic cardiomyopathy is widespread throughout the heart, whereas fibrosis after infarction is limited to the infarcted area, a fact which may render more difficult the ability of cells to penetrate and act in the damaged tissue.

A phase II/III clinical trial sponsored by the Brazilian Ministry of Health, involving 300 chronic chagasic patients designed to evaluate the efficacy of the therapy is being concluded (Tura et al. 2007). This multicentric, randomised, double-blind and placebo-controlled trial started enrolling patients in June 2005 and will allow for a critical evaluation of the efficacy of bone marrowderived cell therapy in the setting of CCC.

Although the results of the clinical trial in patients with Chagas disease are encouraging, we are still in the beginning phases of the development of a new therapy. As for other diseases, there is still a long way ahead in order to achieve a therapy fully capable of reconstituting the organ damaged by many years of chronic disease. It should also be noted that the patients submitted to these first attempts of heart repair had very severe cardiomyopathy and were eligible for cardiac transplantation due to their degree of heart failure. Perhaps an earlier intervention will be more efficient in treating or blocking the evolution of the disease than the same intervention at later stages.

In order to achieve a more efficient therapy, several issues need to be resolved, including the optimal cell population, the number of cells and the number of administrations required. Regarding the cell type, since adult stem cells do not have the same potential to differentiate into cardiomyocytes of ESCs and because these will always be allogeneic cells when used for transplantation in a patient, methods for the genetic modification of adult cells into pluripotent cells are being developed. The reprogramming of adult cells, such as fibroblasts, which can be easily obtained from a biopsy of the patient, has been achieved by the expression of cell factors, generating the so-called induced pluripotent stem. These cells have properties similar to those of ESCs (Takahashi \& Yamanaka 2006, Takahashi et al. 2007) and can be differentiated into cardiomyocytes (Zhang et al. 2009).

Because many transplanted cells die a few days after transplantation (Robey et al. 2008), means to prolong survival and engraftment of these cells are needed. The 
discovery of molecular and cellular mechanisms driving the cells to injured sites and their action may contribute to the development of new strategies for the treatment of Chagas heart disease. If it is proven that the main effect of cellular therapy in heart diseases is a paracrine effect (Fig. 3) due to the secretion of soluble mediators and by the stimulation of endogenous stem cells in their niche, cell therapy may be associated with or even replaced by the delivery of paracrine factors (Cheng \& Yau 2008) to repair the damaged chagasic heart.

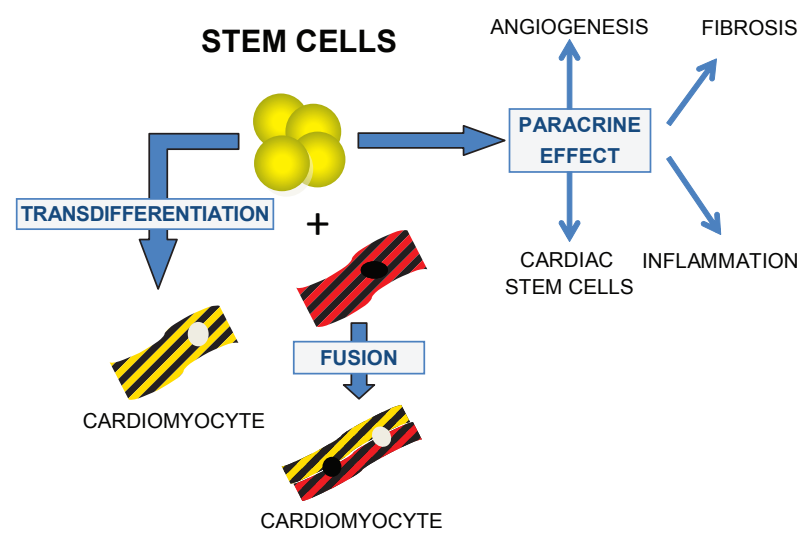

Fig. 3: possible mechanisms of action of transplanted stem cells in chronic chagasic cardiomyopathy (CCC). Initially, stem cells were thought to act by transdifferentiation, acquiring a cardiomyocyte phenotype or by fusion with resident cardiomyocytes. Currently, stem cells seem mainly to act through a paracrine effect, causing a reduction of inflammation and fibrosis, angiogenesis and possibly by stimulating resident cardiac stem cells which can promote de regeneration of the myocardium.

\section{REFERENCES}

Adachi Y, Imagawa J, Suzuki Y, Yogo K, Fukazawa M, Kuromaru O, Saito Y 2004. G-CSF treatment increases side population cell infiltration after myocardial infarction in mice. $\mathrm{J} \mathrm{Mol} \mathrm{Cell} \mathrm{Car-}$ diol 36: 707-710.

Alison MR, Islam S 2009. Attributes of adult stem cells. J Pathol 217: 144-160.

Ballard VL, Edelberg JM 2008. Stem cells for cardiovascular repair - the challenges of the aging heart. J Mol Cell Cardiol 45: 582-592.

Bayes-Genis A, Roura S, Prat-Vidal C, Farré J, Soler-Botija C, de Luna AB, Cinca J 2007. Chimerism and microchimerism of the human heart: evidence for cardiac regeneration. Nat Clin Pract Cardiovasc Med 41: S40-45.

Cançado JR 2002. Long term evaluation of etiological treatment of Chagas disease with benznidazole. Rev Inst Med Trop 44: 29-37.

Cao F, Lin S, Xie X, Ray P, Patel M, Zhang X, Drukker M, Dylla SJ, Connolly AJ, Chen X, Weissman IL, Gambhir SS, Wu JC 2006. In vivo visualization of embryonic stem cell survival, proliferation and migration after cardiac delivery. Circulation 113: 1005-1014.
Carvalho KA, Guarita-Souza LC, Hansen P, Rebelatto CL, Senegaglia AC, Miyague N, Olandoski M, Francisco JC, Furuta M, Gremski W 2006. Cell transplantation after the coculture of skeletal myoblasts and mesenchymal stem cells in the regeneration of the myocardium scar: an experimental study in rats. Transplant Proc 38: 1596-1602.

Cheng AS, Yau TM 2008. Paracrine effects of cell transplantation: strategies to augment the efficacy of cell therapies. Semin Thorac Cardiovasc Surg 20: 94-101.

Cunha-Neto E, Kalil J 1995. Autoimmunity in Chagas' heart disease. Rev Paul Med 113: 757-766.

Dawn B, Guo Y, Rezazadeh A, Huang Y, Stein AB, Hunt G, Tiwari S, Varma J, Gu Y, Prabhu SD, Kajstura J, Anversa P, Ildstad ST, Bolli R 2006. Postinfarct cytokine therapy regenerates cardiac tissue and improves left ventricular function. Circ Res 98: 1098-1105.

Dias JCP, Coura JR 1997. Epidemiologia. In JCP Dias, JR Coura, Clinica e terapêutica da doença de Chagas: uma abordagem prática para o clínico, Ed. Fiocruz, Rio de Janeiro, p. 33-65.

Federici EE, Abelmann WN, Neva FA 1964. Chronic and progressive myocarditis in $\mathrm{C} 3 \mathrm{H}$ mice infected with Trypanosoma cruzi. Am J Trop Med Hyg 13: 272-280.

Garcia S, Ramos CO, Senra JF, Vilas-Boas F, Rodrigues MM, Campos-de-Carvalho AC, Ribeiro dos Santos R, Soares MB 2005. Treatment with benznidazole during the chronic phase of experimental Chagas' disease decreases cardiac alterations. Antimicrob Agents Chemother 49: 1521-1528.

Goldenberg RC, Jelicks LA, Fortes FS, Weiss LM, Rocha LL, Zhao D, Carvalho AC, Spray DC, Tanowitz HB 2008. Bone marrow cell therapy ameliorates and reverses chagasic cardiomyopathy in a mouse model. J Infect Dis 197: 544-547.

Guarita-Souza LC, Carvalho KA, Woitowicz V, Rebelatto C, Senegaglia A, Hansen P, Miyague N, Francisco JC, Olandoski M, Faria-Neto JR, Brofman P 2006. Simultaneous autologous transplantation of cocultured mesenchymal stem cells and skeletal myoblasts improves ventricular function in a murine model of Chagas disease. Circulation 4: 120-124.

Harada M, Qin Y, Takano H, Minamino T, Zou Y, Toko H, Ohtsuka M, Matsuura K, Sano M, Nishi J, Iwanaga K, Akazawa H, Kunieda T, Zhu W, Hasegawa H, Kunisada K, Nagai T, Nakaya H, Yamauchi-Takihara K, Komuro I 2005. G-CSF prevents cardiac remodeling after myocardial infarctionby activating the Jak-Stat pathway in cardiomyocytes. Nat Med 11: 305-311.

Hasegawa H, Takano H, Iwanaga K, Ohtsuka M, Qin Y, Niitsuma Y, Ueda K, Toyoda T, Tadokoro H, Komuro I 2006. Cardioprotective effects of granulocyte colony-stimulating factor in swine with chronic myocardial ischemia. J Am Coll Cardiol 47: 842-849.

Higashiyama R, Inagaki Y, Hong YY, Kushida M, Nakao S, Niioka M, Watanabe T, Okano H, Matsuzaki Y, Shiota G, Okazaki I 2007. Bone marrow-derived cells express matrix metalloproteinases and contribute to regression of liver fibrosis in mice. Hepatology 45: 213-222.

Higuchi ML 1997. Chronic chagasic cardiopathy: the product of a turbulent host-parasite relationship. Rev Inst Med Trop São Paulo 39: 53-60.

Hodgson DM, Behfar A, Zingman LV, Kane GC, Perez-Terzic C, Alekseev AE, Pucéat M, Terzic A 1994. Stable benefit of embryonic stem cell therapy in myocardial infarction. Am J Physiol Heart Circ Physiol 287: H471-479.

Jacob JL, Salis FV, Ruiz MA, Greco OT 2007. Labeled stem cells transplantation to the myocardium of a patient with Chagas' disease. Arq Bras Cardiol 89: e10-11. 
Kajstura J, Urbanek K, Rota M, Bearzi C, Hosoda T, Bolli R, Anversa P, Leri A 2008. Cardiac stem cells and myocardial disease. J Mol Cell Cardiol 45: 505-513.

Kang S, Yang YJ, Li CJ, Gao RL 2008. Effects of intracoronary autologous bone marrow cells on left ventricular function in acute myocardial infarction: a systematic review and meta-analysis for randomized controlled trials. Coron Artery Dis 19: 327-335.

Kawada H, Fujita J, Kinjo K, Matsuzaki Y, Tsuma M, Miyatake H, Muguruma Y, Tsuboi K, Itabashi Y, Ikeda Y, Ogawa S, Okano H, Hotta T, Ando K, Fukuda K 2004. Nonhematopoietic mesenchymal stem cells can be mobilized and differentiate into cardiomyocytes after myocardial infarction. Blood 104: 3581-3587.

Klug MG, Soonpaa MH, Koh GY, Field LJ 1996. Genetically selected cardiomyocytes from differentiating embryonic stem cells form stable intracardiac grafts. J Clin Invest 98: 216-224.

Köberle F 1968. Chagas' disease \& Chagas' syndromes: the pathology of American trypanosomiasis. Adv Parasitol 6: 63-116.

Kocher AA, Schuster MD, Szabolcs MJ, Takuma S, Burkhoff D, Wang J, Homma S, Edwards NM, Itescu S 2001. Neovascularization of ischemic myocardium by human bone-marrow-derived angioblasts prevents cardiomyocyte apoptosis, reduces remodeling and improves cardiac function. Nat Med 7: 430-436.

Laflamme MA, Gold J, Xu C, Hassanipour M, Rosler E, Police S, Muskheli V, Murry CE 2005b. Formation of human myocardium in the rat heart from human embryonic stem cells. Am J Pathol 167: 663-671.

Laflamme MA, Murry CE 2005a. Regenerating the heart. Nat Biotechnol 23: 845-856.

Le Blanc K, Ringdén O 2007. Immunomodulation by mesenchymal stem cells and clinical experience. J Intern Med 262: 509-525.

Leon JS, Daniels MD, Toriello KM, Wang K, Engman DM 2004. A cardiac myosin-specific autoimmune response is induced by immunization with Trypanosoma cruzi proteins. Infect Immun 72: 3410-3417.

Leon JS, Engman DM 2001. Autoimmunity in Chagas heart disease. Int J Parasitol 31: 555-561.

Makino S, Fukuda K, Miyoshi S, Konishi F, Kodama H, Pan J, Sano M, Takahashi T, Hori S, Abe H, Hata J, Umezawa A, Ogawa S 1999. Cardiomyocytes can be generated from marrow stromal cells in vitro. J Clin Invest 103: 697-705.

Menard C, Hagege AA, Agbulut O, Barro M, Morichetti MC, Brasselet C, Bel A, Messas E, Bissery A, Bruneval P, Desnos M, Pucéat M, Menasché P 2005. Transplantation of cardiac-committed mouse embryonic stem cells to infarcted sheep myocardium: a preclinical study. Lancet 366: 1005-1012.

Minatoguchi, S, Takemura G, Xue-Hai C, Wang N, Uno Y, Koda M, Arai M, Misao Y, Lu C, Suzuki K, Goto K, Komada A, Takahashi T, Kosai K, Fujiwara T, Fujiwara H 2004. Acceleration of the healing process and myocardial regeneration may be important as a mechanism of improvement of cardiac function and remodeling by postinfarction granulocyte colony-stimulating factor treatment. Circulation 109: 2572-2580.

Moreira DR, Leite AC, Ribeiro dos Santos R, Soares MB 2009. Approaches for the development of new anti-Trypanosoma cruzi agents. Curr Drug Targets 10: 212-231.

Olivares EL, Ribeiro VP, Werneck de Castro JPS, Ribeiro KC, Mattos EC, Goldenberg RC, Mill JG, Dohmann HF, Ribeiro dos Santos R, de Carvalho AC, Masuda MO 2004. Bone marrow stromal cells improve cardiac performance in healed infarcted rat hearts. Am J Physiol Heart Circ Physiol 287: H464-H470.
Oliveira SA, Souza BS, Guimaraes-Ferreira CA, Barreto ES, Souza SC, Freitas LA, Ribeiro dos Santos R, Soares MB 2008. Therapy with bone marrow cells reduces liver alterations in mice chronically infected by Schistosoma mansoni. World J Gastroenterol 14: $5842-5850$.

Orlic D, Kajstura J, Chimenti S, Bodine DM, Leri A, Anversa P 2001. Bone marrow cells regenerate infarcted myocardium. Nature 410: 701-705.

Ott HC, Matthiesen TS, Goh SK, Black LD, Kren SM, Netoff TI, Taylor DA 2008. Perfusion-decellularized matrix: using nature's platform to engineer a bioartificial heart. Nat Med 14: 213-221.

Perino MG, Yamanaka S, Li J, Wobus AM, Boheler KR 2008. Cardiomyogenic stem and progenitor cell plasticity and the dissection of cardiopoiesis. J Mol Cell Cardiol 45: 475-494.

Pittenger MF, Mackay AM, Beck SC, Jaiswal RK, Douglas R, Mosca JD, Moorman MA, Simonetti DW, Craig S, Marshak DR 1999. Multilineage potential of adult human mesenchymal stem cells. Science 284: 143-147.

Pontes-de-Carvalho L, Santana CC, Soares MBP, Oliveira GG, Cunha-Neto E, Ribeiro dos Santos R 2002. Experimental chronic Chagas' disease myocarditis is an autoimmune disease preventable by induction of immunological tolerance to myocardial antigens. J Autoimmun 18: 131-138.

Reinecke H, MacDonald GH, Hauschka SD, Murry CE 2000. Electromechanical coupling between skeletal and cardiac muscle. Implications for infarct repair. J Cell Biol 149: 731-740.

Ribeiro dos Santos R, Mengel JO, Postol E, Soares RA, FerreiraFernandez E, Soares MB, Pontes-De-Carvalho LC 2001. A heart-specific $\mathrm{CD} 4^{+} \mathrm{T}$-cell line obtained from a chronic chagasic mouse induces carditis in heart-immunized mice and rejection of normal heart transplants in the absence of Trypanosoma cruzi. Parasite Immunol 23: 93-101.

Ribeiro dos Santos R, Rossi MA, Laus JL, Silva JS, Savino W, Mengel J 1992. Anti-CD4 abrogates rejection and reestablishes long-term tolerance to syngeneic newborn hearts grafted in mice chronically infected with Trypanosoma cruzi. J Exp Med 175: 29-39.

Robey TE, Saiget MK, Reinecke H, Murry CE 2008. Systems approaches to preventing transplanted cell death in cardiac repair. J Mol Cell Cardiol 45: 567-581.

Rocha NN, Garcia S, Gimenez LE, Hernández CC, Senra JF, Lima RS, Cyrino F, Bouskela E, Soares MB, Ribeiro dos Santos R, Campos de Carvalho AC 2006. Characterization of cardiopulmonary function and cardiac muscarinic and adrenergic receptor density adaptation in C57BL/6 mice with chronic Trypanosoma cruzi infection. Parasitology 133: 729-737.

Scorsin M, Hagège A, Vilquin JT, Fiszman M, Marotte F, Samuel JL, Rappaport L, Schwartz K, Menasché P 2000. Comparison of the effects of fetal cardiomyocyte and skeletal myoblast transplantation on postinfarction left ventricular function. J Thorac Cardiovasc Surg 119: 1169-1175.

Soares MB, Garcia S, Campos de Carvalho AC, Ribeiro dos Santos R 2007. Cellular therapy in Chagas' disease: potential applications in patients with chronic cardiomyopathy. Regen Med 2: 257-264.

Soares MBP, Lima RS, Rocha LL, Takyia CM, Pontes-de-Carvalho L, de Carvalho AC, Ribeiro dos Santos R 2004. Transplanted bone marrow cells repair heart tissue and reduce myocarditis in chronic chagasic mice. Am J Pathol 164: 441-447.

Soares MBP, Pontes-de-Carvalho L, Ribeiro dos Santos R 2001. The pathogenesis of Chagas' disease: when autoimmune and parasite-specific immune responses meet. An Acad Bras Cienc 73: $547-559$. 
Takahashi K, Okita K, Nakagawa M, Yamanaka S 2007. Induction of pluripotent stem cells from adult human fibroblasts by defined factors. Cell 131: 861-872.

Takahashi K, Yamanaka S 2006. Induction of pluripotent stem cells from mouse embryonic and adult fibroblast cultures by defined factors. Cell 126: 663-676.

Tarleton RL 2001. Parasite persistence in the aetiology of Chagas disease. Int J Parasitol 31: 550-554.

Taylor DA, Zenovich AG 2008. Cardiovascular cell therapy and endogenous repair. Diabetes Obes Metab 10: 5-15.

ten Hove WR, Verspaget HW, Barge R, Lamers CB, van Hoek B 2007. Liver chimerism after allogeneic blood stem cell transplantation. Transplant Proc 39: 231-236.

Toma C, Pittenger MF, Cahill KS, Byrne BJ, Kessler PD 2002. Human mesenchymal stem cells differentiate to a cardiomyocyte phenotype in the adult murine heart. Circulation 105: 93-98.

Tura BR, Martino HF, Gowdak LH, Ribeiro dos Santos R, Dohmann HF, Krieger JE, Feitosa G, Vilas-Boas F, Oliveira SA, Silva SA,
Bozza AZ, Borojevic R, Campos de Carvalho AC 2007. Multicenter randomized trial of cell therapy in cardiopathies - MiHeart Study. Trials $8: 2$.

Vilas-Boas F, Feitosa GS, Soares MBP, Mota A, Pinho-Filho JA, Gonçalves Almeida AJ, Andrade MV, Carvalho HG, DouradoOliveira A, Ribeiro dos Santos R 2006. Early results of bone marrow cell transplantation to the myocardium of patients with heart failure due to Chagas disease. Arq Bras Cardiol 87: 159-166.

Vilas-Boas F, Feitosa GS, Soares MB, Pinho-Filho JA, Mota A, Almeida AJ, Carvalho C, de Carvalho HG, de Oliveira AD, Ribeiro dos Santos R 2004. Bone marrow cell transplantation to the myocardium of a patient with heart failure due to Chagas' disease. Arq Bras Cardiol 82: 185-187.

Wang JS, Shum-Tim D, Chedrawy E, Chiu RC 2001. The coronary delivery of marrow stromal cells for myocardial regeneration: pathophysiologic and therapeutic implications. J Thorac Cardiovasc Surg 122: 699-705.

Zhang J, Wilson GF, Soerens AG, Koonce CH, Yu J, Palecek SP, Thomson JA, Kamp TJ 2009. Functional cardiomyocytes derived from human induced pluripotent stem cells. Circ Res 104: e30-41. 